\title{
Capturing motivation and emotion regulation during a learning process
}

\section{Hanna Järvenoja a, Sanna Järveläa, Tiina Törmänen ${ }^{a}$, Piia Näykkia , Jonna Malmberga Kristiina Kurki ${ }^{a}$, Arttu Mykkänen ${ }^{a}$, Jaana Isohätäläa}

\author{
${ }^{\text {a }}$ Learning \& Educational Technology Research Unit (LET), University or Oulu, Finland \\ Article received 14 May 2018 /revised 12 September /accepted 20 October /available online 7 December
}

\begin{abstract}
This paper describes our research approach in which we have focused on situational and contextual variations in motivation and emotion regulation to better understand its role, appearance and function in collaborative learning situations. We have used research designs that employ process-oriented measures combined with subjective interpretations to capture motivation and emotion regulation. Analysing on-line process data poses several challenges such as variation in the granularity of different data sources, problems that emerge due to the complexity of contextual and situational factors in ecologically-valid learning situations or, currently, challenges in the use of multiple data channels and their analyses.

In this paper, we present three claims underlying our research, particularly the motivation and emotions and their regulation in learning. The claims are as follows: (1) motivation and emotion regulation is situation and context specific, (2) motivation and emotion regulation is influenced by multi-layered nature of motivation and (3) Motivation and emotion regulation is intertwined with other processes of learning and can be captured from their temporal manifestation. We present an example from our empirical study to discuss how these claims have led us to employ multiple process-oriented methods that include both subjective and objective data sources, including different combinations of situation-specific self-reports, video and physiological data. We then describe opportunities and challenges involved in the empirical studies.
\end{abstract}

Keywords: Self-regulated Learning; Emotion Regulation; Motivation Regulation; Multiple Data Channels 
Järvenoja et al

\section{Introduction}

The role of emotions and motivation in fostering learning and achievement has been acknowledged in the field of learning sciences (Linnenbrink-Garcia, \& Pekrun, 2011; Pekrun, Goetz, Titz, \& Perry, 2002). Theories on motivation and emotions in learning cover multiple concepts and theoretical models explaining the relationship between learners' beliefs and feelings in learning (Pekrun, 2016). Motivation theories are particularly involved in describing the reasons why and how learners pay attention to, concentrate on, invest effort in and persist during their academic learning (Schutz \& Pekrun, 2007; Volet \& Järvelä, 2001). Still, theories of motivation and emotion have been criticised from not translating self-evidently into classroom practices (Boekaerts \& Corno, 2005; Dignath, Buettner, Langfeldt, \& Goethe, 2008; Pintrich, 2003). Too often, motivational constructs are well recognised in research but do not have sufficient practical implications in to real learning contexts. This may stem from research approaches that study certain motivational components in isolation from the actual learning process, limiting the complex and still unclear issue of the dynamic relationships between context and motivation to a background variable (Volet \& Järvelä, 2001; Volet \& Vauras, 2013). Many conventional self-reports of students' emotions and motivation, for example, measure students' appraisals and perceptions of their emotional or motivational experiences, but do not explore how motivation and emotions are situated and realised in the learning context or how they fluctuate between situations or over time (Järvelä, Salonen, \& Lepola, 2001; Paris \& Turner, 2012; Winne \& Perry 2000).

We argue that one way to make research on motivation and emotion more effective is to develop research designs and methods that capture the dynamics of students' emotions and motivational factors during the learning process in ecologically-valid, authentic, learning contexts (Pekrun, 2016). Accordingly, we engage a process-oriented perspective on studying motivation and emotion regulation as a part of self-regulated learning (SRL). SRL theory provides us with a theoretical framework that allows us to bring the situational and contextual variation of learners' motivation and emotions into the focus by targeting their actualized regulation of motivation and emotions (Boekaerts \& Pekrun, 2015; Pintrich, 2000; Zimmerman \& Schunk, 2011; Winne \& Hadwin, 1998). It emphasises motivation and emotions as essential features of the learners' commitment in a learning situation and offers a way to conceptually and empirically grasp the multiple layers of motivation and emotions that are realized in the regulation actions in-situ (Järvenoja, Järvelä, \& Malmberg, 2015; Volet, Vauras, \& Salonen, 2009). As for engaging in emotion regulation in the learning situation, learners regulate their affect and emotional experience to ensure emotionally solid (social) ground for completing academic tasks (Boekaerts \& Pekrun, 2015; Pekrun, 2016). Emotion regulation is required, for example, to reduce negative affective responses in a socio-emotionally challenging situation or harmful effects of emotional experiences for learning and academic performance. Regulation of motivation is composed of purposeful and appropriate strategic activities through which individuals or group members in coordination initiate, control, and supplement their willingness to maintain the learning process and achieve learning goals (Boekaerts \& Pekrun, 2015). Motivation regulation can be directed, for example, at strengthening or redirecting interest, motivational goals or self-efficacy beliefs (Wolters \& Benzon, 2013).

Finally, we have built our research approach on empirical evidence that emphasises that group members' motivation and emotions and their effects on learning cannot be thoroughly comprehended without considering the social context in which they occur (Dowson \& McInerney, 2003; Hickey \& McCaslin, 2001; Volet \& Järvelä, 2001). All learning includes social dimensions and is inherently social, but the meaning of the social context and interaction is particularly essential in collaborative learning contexts (Baker, 2015). Collaborative learning has become an essential $21^{\text {st }}$ century skill (Griffin, McGaw, \& Care, 2012; Sawyer, 2014); its benefits for learning have been emphasised by many researchers (Miyake, 1986; Roschelle \& Teasley, 1995; Webb, Troper, \& Fall, 1995), and collaborative learning has also become an increasingly valued teaching and learning practise in schools. Motivation and emotion regulation in collaborative learning has been characterized as a fundamental part of effective collaborative learning interactions as a part of an increasing interest in defining the regulation mechanism of the groups (Hadwin, Järvelä, \& Miller, 2018). Lately, the research has become increasingly interested in exploring how motivation and emotion regulation function and fluctuate during collaborative learning situations, and for example, when and how group members share the regulatory responsibilities (Järvenoja, Järvelä, \& Malmberg, 2017). However, compared to progress in 
research on groups' cognitive regulation mechanism, studies focusing on motivation and emotion regulation in collaborative learning situations are still scarce.

In this paper, we introduce our research approach by presenting three claims that address the investigation of motivation and emotion regulation in-situ, describe our methodological orientation and justify the choices of implemented methods. While the three claims overlap somewhat, each claim aims to underlie certain aspects of the research approach. The first claim, motivation and emotion regulation is situation and context specific, grounds our choice of investigating motivation and emotion regulation in authentic learning contexts. The second claim, motivation and emotion regulation is influenced by the multi-layered nature of motivation, gives reasons why it is not enough to focus solely on traceable regulation activities but to complement process data on regulation activities with other measures that capture different components of individual beliefs and interpretations about their motivation and emotions. Finally, with the third claim, motivation and emotion regulation is intertwined with other processes of learning and can be captured from its temporal manifestation, we introduce our recent endeavours to explore the possibilities of employing data on group members' reactions in tracing meaningful situations in terms of motivation and emotion regulation. In relation to the claims, we illustrate with an empirical case example our methodological decisions and highlight the possible advantages and challenges. Altogether, the three claims illustrate how the implementation of process analysis does not derive from a simple desire to adopt a certain choice of method(s) but a research agenda that influences the choices made, from the research design to the analysis.

\section{Claim: Motivation and emotion regulation is situation and context specific}

The first claim, motivation and emotion regulation is situation and context specific, has directed our choices for research contexts towards ecologically valid learning settings where the students collaborate as a part of their regular studying (Järvenoja et al., 2015; Volet \& Järvelä, 2001). Studies that are carried out in these situations where students have an authentic need to overcome possible challenges in their collaboration (F. Kirschner, Paas, \& Kirschner, 2011) enable to us to analyse motivation and emotion regulation in a context that is not isolated but includes all the situational and contextual features that affect to the activation of motivation and emotion regulation. Following a situated perspective on learning (Greeno, 2005), a learner enters into the learning situation with unique, socio-historically founded personal motivational beliefs and emotional experiences. However, these structures are not static but contextually and situationally changing (Volet \& Järvelä, 2001). Each situation forms a unique composition of different factors that together form the circumstances for learning and regulation. Situational and contextual factors such as social interaction and the nature of the task, mediate the need for motivation and emotion regulation and, correspondingly, through motivation and emotion regulation the beliefs and experiences can be actively changed or modified in the situation (Isohätälä, Järvenoja, \& Järvelä, 2017; Kurki, Järvenoja, Järvelä, \& Mykkänen, 2017; Mykkänen, Perry, \& Järvelä, 2017; Whitebread et al., 2009). Therefore, regulation of motivation and emotions is socially situated, involving a dynamic interplay between learners, tasks, teachers, peers and parents and is bound up with the context (Hadwin et al., 2017; Järvenoja, et al., 2015). This has led us to carry out studies where development of situational challenges creates the need for motivation and emotion regulation as well as the actual manifestation of such a regulation is followed from collaborative groups' learning process. In these case studies, the main source of data has typically been video recorded group activities.

For example, the study by Järvenoja, Näykki, Törmänen, and Järvelä (2018) implemented momentby-moment video analysis with 30-second time segments as a unit of analysis to locate the situation-specific challenges and related group-level emotion regulation strategies during higher education students' $(\mathrm{N}=62$; mean age 23 years) mathematics' class. The course was part of the students' regular study program and the course design involved collaborative learning tasks that were videotaped. The results from 87 hours of video recordings showed that a wide range of challenges $(f=1301$ events $)$ emerged in groups, covering challenges with cognitive, motivational and emotional issues, and different socially- and contextually-oriented challenges. The study also followed how emotion regulation was enacted during these different challenging situations and revealed that emotion regulation was not bound merely to one type of challenge situation, but all of the challenging situations could potentially trigger group-level regulation. Again, the type of regulation (co- vs. 
socially-shared) was interconnected with the experienced challenge. Co-regulation was used, for example, to increase awareness of the emotional aspects whereas socially-shared emotion regulation was more typically used when social reinforcement was manifested.

Overall, the above example illustrates how emotion and motivation are bound to the context in which it takes place. Particularly, the triggers that activated group members' co- and socially-shared regulation emerge from the current situation and were bound to different contextual features. Methodologically speaking, how regulation emerged in the group situations and how regulation interacted in relation to the experienced challenges could not be found if the collaborative learning process was not analysed with micro-level video analyses. Studying motivation and emotion regulation in detail as a part of the learning process is essential for recognising and understanding the phenomenon and for operationalising the different indicators of motivation and emotion regulation from the process data. The clear advantage of this type of micro-level video analysis is that it allows the possibility of following how the regulatory behaviours, contextual conditions for motivated learning both shape and are shaped by the situational circumstances of a given time and place. This is important for understanding the mechanisms of emotion and motivation regulation in collaborative learning. Detailed video data analysis illustrates the changing composition of interactions, context and activities that give rise to self-regulation, co-regulation and shared regulation of motivation and emotions in the situation (Hadwin et al., 2017). Process data from these unique situations helps to study motivation, emotions and their regulation 'in action' in different context and situations.

The pitfall is that contextualized, detailed analysis of video data does not allow for the exploration of the phenomena in a more generalisable manner. Case analysis provides understanding and provokes new research questions but for examining, for example, temporal traces and patterns of motivation and emotion regulation, larger data sets are needed (Malmberg, Järvenoja, \& Järvelä, 2013). Our challenge has also been that operationalisation of different components of analysis, such as a 'challenging situation', is not specific enough to be transferred to the systematic analysis of larger data sets as it would be extremely time-consuming (see also Wise \& Schwarz, 2017). For example, in the above described example, the analysis phases included several rounds of categorizing the 87 hours of video data corpus to first reliably locate the challenges and the related regulation. Regardless of a growing number of developed methods, such as video recording systems and different state-of-the-art technology tools that make it possible to capture classroom interaction, it has still been difficult to process video data systematically when emotion and motivation regulation is traced from group members' interactions (Azevedo, Moos, Johnson, \& Chauncey, 2010). This is particularly challenging as the results tend to suggest repeatedly that while regulation of motivation and emotion is critical for collaborative groups, their occurrence during collaboration is rare and situation specific (Järvenoja et al., 2017; Sobocinski, Malmberg, \& Järvelä, 2017). This poses a challenge for analysis; even with relatively large video data, the frequency of the coded episodes remains low, limiting considerably the possibilities for analysis and generalisation. However, it also relates to the main premise of our first claim; the triggers for groups to activate emotion and motivation regulation are context-bound, encompassing a situated combination of different features. Much more evidence covering a critical mass of process data is required to confirm the role and meaning of emotion and motivation for regulated learning progress.

Finally, the analysis of motivation and emotion regulation solely from video data is limited to visible reactions and verbalised expressions, leaving out motivational and emotional processes that are silent and hence, invisible to traditional video observation. Even though this type of research design provides valuable instruments and methods for context- and task-specific measures to explore regulatory actions as they occur in real time, it is not possible to reach individual internal reactions, beliefs and interpretations of the situation solely with process data. The pitfall is that the researcher relies on his/her interpretations of the phenomena on the verbal and non-verbal behaviours of the learners, but does not know the actual reasons behind them. This leads us to the next claim. 


\section{Claim: Motivation and emotion regulation is influenced by the multi-layered nature of motivation}

Our second claim, motivation and emotion regulation is influenced by the multi-layered nature of motivation, refers to the multiple ways and levels in which motivation and emotions function in learning. We started the first claim by arguing that motivation and emotions in the situation are dependent on both learners' prior socio-historical experiences and social contexts (Elliot et al., 2016; Levy, Kaplan, \& Patrick, 2004; Nolen, Horn, \& Ward, 2015). The multiple emotional and motivational factors, namely appraisals, expectancies, values, beliefs and goals, together form the (pre)conditions for motivation and emotion regulation (Pekrun, 2016). The learning situations are built on these conditions, indicating that learner approaches and decision-making processes are personalised by prior individual and group experiences over time and events (Hadwin, Järvelä, \& Miller, 2017). Even though 'objective' process methods, (e.g., video records or log traces that accumulate from technology-based learning environments) can provide rich accounts of learners' and groups' actions and visible reactions in the moment, understanding reasons behind these actions require 'subjective data' (e.g., questionnaires, diaries, interviews) (Berger \& Karabenick, 2016; Fincham et al., 2018; Järvelä, Malmberg, Sobocinski, Haataja, \& Kirschner, 2018; Malmberg et al., 2013).

One of our first efforts to develop measures to capture individual beliefs in a specific learning situation was the development of an instrument, called Adaptive Instrument for Regulation of Emotions (AIRE) (Järvenoja, Volet, \& Järvelä, 2013), which is a self-report instrument designed to access students' experiences of individual and socially-shared regulation of emotions repeatedly in a specific group learning activity. The instrument is comprised of four interrelated sections, each with a different focus. These four components identify (1) personal goals, (2) the socio-emotional challenges experienced while studying in a collaborative situation, (3) group members' own evaluation of their individual and group-level attempts to regulate the immediate emotions evoked by the challenges, and (4) reflections on personal goal attainment in the learning situation and how the collaborative group work contributed to it. As each group members' response to the AIRE is individual, it is sensitive to students' unique experiences. The AIRE instrument enables analyses that compare the coherence between individual group members' appraisals of the reasons for socio-emotional challenges within specific learning situations, their personal goals and satisfaction with collaborative learning experience. Consequently, it captures the regulatory process of the whole group. Furthermore, when group members' responses to different components of the AIRE instrument are compared, it is possible to form a group-level interpretation of the situation (Järvenoja \& Järvelä, 2009). This affords the possibility of moving the focus when needed to a group level and to provide an estimation of the groups' joint understanding of the experienced socio-emotional challenges and motivation and emotion regulation. In its entirety and choice of analytical possibilities, AIRE is an example of subjective self-report instruments that support our preliminary assumptions of ecologically valid, situation-specific and process-oriented measures. While self-report measures have been criticised as being too stable and trait oriented (Winne \& Perry, 2000), the need for selfreports cannot be neglected since they access the self-perceptions of individual learners (Bandura, 2011; McCardle \& Hadwin, 2015). Rather, we emphasise that process-oriented analysis should not be construed as a substitute for learners' subjective appraisals but if the form of self-reports is purposefully considered, they can become an approach that reaches beyond the observable or measurable reactions and behaviours and provides the possibility of focusing on learner experiences (Koskey, Karabenick, Woolley, Bonney, \& Dever, 2010; Nolen, 2006).

To study motivation and emotion regulation as a multi-layered phenomenon and as a part of the learning process, however, presumes going beyond recognising and capturing the subjective interpretations and explanations or focusing solely on the process data. As we have argued above, the process in which the effects of motivational and emotional conditions actualise into products of learning and motivation regulation are composed of both individual beliefs and processes taking place in the situation (Bakhtiar, Webster, \& Hadwin, 2018). Subjective data (e.g., repeated and contextualised self-reports) can reveal students' intentions to learn and the type of beliefs they have about themselves as learners (McCardle \& Hadwin, 2015). Conversely, objective data (e.g., video and log data, eye movements and physiological responses) provide continuous information about behavioural and mental indicators such as confusion and increasing effort or attention, which are almost impossible to capture otherwise. When the two types of data sources are combined, we can both trace occurrence of emotion and motivation regulation and explain the conditions and products it is bound to (Bakhtiar et al., 2018). Näykki, Järvelä, Kirchner, \& Järvenoja. (2014), for example, combined 
video-observation data with video-stimulated recall interview data to follow and explain how higher education student collaboration led to a severe socio-emotional conflict. The group dynamics and task characteristics were depicted through process analysis of video data that revealed emerging motivational (e.g., task commitment problems) and emotional (e.g., frustration due to overruling interaction) challenges. The personal reasons behind the conflict was then revealed in the video-stimulated interviews where group members' provided individual, subjective explanations for the experienced challenges. The combination of two data sources explained why one of the groups failed in regulation of their emotions and motivation, while the other groups managed to regulate the challenging situations.

In our ongoing study, we have moved forward in specific operationalisation of the situational indicators of challenges that include triggers for activating emotion and motivation regulation. We have collected data from 12-year old primary school students $(n=41)$, as they collaborated in three-member groups to complete a design task to construct a model of an energy-efficient house making use of solar energy. Apart from process data comprised of video-taped working and physiological data (see Claim 3 for more details), both general level and situated self-reports were collected. General level self-reports captured two different motivational constructs: individual students' self-efficacy beliefs (Usher \& Pajares, 2008) and interest towards science (Cleary, 2006) and self-reported beliefs regarding students' self-regulation skills (Cleary, 2006). Situated self-reports measured individual group members' perceived valence of emotional state with the emotion awareness tool (EmA) before and after the group task. At the end of the collaborative task, students also evaluated their satisfaction towards the collaborative work of their group.

In the part of the data analysis that makes use of the subjective self-report data to explain the actualised motivation and emotion regulation captured from video data, we are currently focusing on the self-reported valence measured before and after the collaborative learning session and its relation to actualised regulation in collaborative learning episodes having a negative group-level valence (Kurki, Järvenoja, Törmänen, \& Bakhtiar, 2018). While self-reported EmA data provides us the individual accounts of students' self-perceived emotional valence in the situation, the analysis of video data extends the analysis on the process level, exploring the characteristics of the group process in terms of socio-emotional interactions, their valences, and actualised regulation of motivation and emotions. The analysis of the process data began by depicting the groups' socio-emotional interaction episodes from the video data corpus. Emotional valence and related emotion and motivation regulation were then coded in relation to these episodes. The video data was processed using Observer XT software. The valence coding protocol categorization is presented in Table 1 as an example of our typical video coding protocol. The table explicitly states how individual-level emotional indicators are translated into a group level emotional valence in the coding. It also provides examples of motivation and emotion regulation that may emerge in relation to these episodes.

Table 1

An example of coding categories for emotional valence

\begin{tabular}{|c|c|c|c|c|}
\hline $\begin{array}{l}\text { Emotional } \\
\text { Valence }\end{array}$ & Coding criteria & Indicators & $\begin{array}{l}\text { Example emotions } \\
\text { (Kreibig, 2010; } \\
\text { Linnenbrink-Garcia } \\
\text { et al., 2011; Pekrun } \\
\text { et al., 2002; Russell } \\
\text { \& Barrett, 1999) }\end{array}$ & $\begin{array}{l}\text { Examples of related } \\
\text { emotion and } \\
\text { motivation } \\
\text { regulation }\end{array}$ \\
\hline
\end{tabular}


Positive

Clear positive indicator from at least two of the group members, another group members cannot be indicating negative emotions
Verbal signs (e.g. 'We are so good')

Bodily signs (e.g. laughing, giggling)

Positively charged interaction (e.g. joking, praising, encouraging)
Excitement, happiness, enjoyment, hope, pride, relief

Negative

Clear negative
indicators from
at least two of
the group
members,
another group
members cannot
be indicating
positive
emotions

Verbal signs (e.g. 'We are idiots')

Bodily signs (e.g. sighing)

Lack of focus (e.g. playing with equipment, wandering around)

Negatively charged interaction (e.g. arguing, criticising others, teasing)

Tensioned silence

Anger, anxiety, frustration, annoyance, shame, disgust, fear, hopelessness, boredom

"I feel like you are the best at drawing these geometric things, so if you draw like, this and then kind of a hole there.."

"Window hole. Can this be wider? Can this be a bit wider?"

"Yes it can. You know how to draw."

(Co-regulation)

"This is the ugliest house in the world"

"Who would ever want to live in a house like this"

"Well whatever, at least we had a good idea"

"At least we have more windows than some..."

(Socially shared regulation)

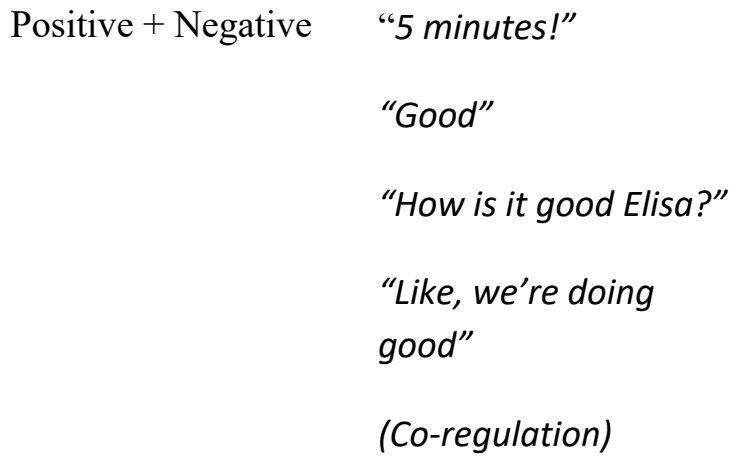




\begin{tabular}{|c|c|c|c|}
\hline Unclear & $\begin{array}{l}\text { Multiple } \\
\text { emotional } \\
\text { indicators, both } \\
\text { positive and } \\
\text { negative (e.g. } \\
\text { positive bodily } \\
\text { sign + negative } \\
\text { verbal sign) }\end{array}$ & $\begin{array}{l}\text { Emotional valence is } \\
\text { not clear }\end{array}$ & $\begin{array}{l}\text { Emotional valence is } \\
\text { not clear }\end{array}$ \\
\hline
\end{tabular}

After operationalising and coding the different components, the analysis proceeded to compare negative socio-emotional episodes and related group-level regulation with individual student reports on their emotional valence before and after the task. The statistical correlations between the variables were calculated using the estimates of Spearman's correlation coefficient, and the preliminary results indicate that students' negative emotional states before the task did not increase negative interactions, but actually promoted regulation of motivation and emotion during the negative interactions (Kurki et al., 2018). No clear connection was found between the actualised regulation and the valence. However, the self-perceived valence increased in general after the task. The next step is to add a new layer by adding the general self-report data to the analysis.

The advantages of combining subjective interpretations with process data analysis lie in the possibility of tracing the dual relationship between individual beliefs and actualised regulation at the group level. In the above example, this meant that by collecting the student evaluations before and after the learning task, we were able to first investigate how emotional valence was reflected in the regulation during the collaborative learning task, and second, how regulation may have modified the individual student's emotional valence after the group task. When the data on more general-level beliefs is added to the analysis, it will be possible to analyse how subjective beliefs about motivation and emotion in learning shape the students' preconditions to the collaborative learning and thus, to explore how these beliefs shape the motivation and emotion regulation and, vice versa, how the regulation processes shape students' future motivational beliefs and emotional experiences. Furthermore, combining these multiple layers provides the possibility of exploring in more detail what characterizes the socio-emotional interactions and their co- and socially-shared regulation (Järvelä; Järvenoja, \& Veermans, 2008; Hadwin et al., 2017).

It is an advantage from both theoretical and methodological perspectives to combine multiple data sources that capture different dimensions of motivation and emotions instead of relying on a sole source of data (Ochoa, 2017). When individual subjective meaning is emphasised as the conditions upon which the contextual interpretations are made, data on these subjective appraisals cannot be neglected. Different data sources provide possibilities for data triangulation (Azevedo, 2015). This is essential particularly when the theoretical definition and empirical evidence is still evolving. However, the implementation of multiple data sources that are operationally distinct from each other does not come without pitfalls. When merging subjective interpretation data with process data analysis, we first deal with the challenges of different types of data sources (Winne \& Perry, 2000). However, the main challenge we face is consolidation of data gathered with different methods. We are constantly struggling, for example, to find meaningful correlations with individual self-report data, learning outcomes and process data from student interaction (e.g., Winne \& Jamieson-Noel, 2002). While this could be an indication of inaccurate selection of certain instruments or data analysis protocol, it could also derive from differences in granularity size of different data sources or the unit of the analysis. Typically, the number of participants in the studies that collect process data from real-life collaborative learning is low, which restricts the possibility of self-report data, particularly when we want to engage group-level analysis when the total number of participants is further divided into the number of the collaborative groups. The amount of equipment, space, student groups, etc. that the process data collection in authentic collaborative learning tasks requires is also a bottleneck. While collecting process data from multiple sessions cumulates the data mass, 
and partly also the situated self-report data mass, the total number of participants remains relatively low as was seen in above example. To summarise, multi-layered process data collection sets challenges for a) combining different data sources, b) combining and selecting instruments that would be comparable and theoretically valid with each other and process data, c) recruiting a sufficient number of participants and finally, d) having an infrastructure that enables the collection of process data in ecologically valid settings.

\section{Claim: Motivation and emotion regulation is intertwined with other processes of learning and can be captured from their temporal manifestation.}

The third claim, motivation and emotion regulation is intertwined with other processes of learning and can be captured from their temporal manifestation, refers to our latest empirical endeavours to find ways to more systematically explore the different sub-processes that can trigger or indicate the emergence of motivation and emotion regulation during collaborative learning. While we know that co- and socially-shared regulation appears at low incidence that are interconnected with situation (Järvenoja et al, 2018), to progress with research, we are destined to explore ways of locating and analysing motivation and emotion regulation more systematically from the learning process, in parallel, embedded and interdependent with other motivational and emotional processes and in relation to cognitive manifestation of regulated learning (Hadwin et al., 2017; Järvelä \& Hadwin, 2013; Järvelä, Järvenoja, Malmberg, Isohätälä, \& Sobocinski, 2016). In the majority of studies implementing multiple process data, the operationalisation of regulatory interactions and behaviours are limited to 'cognitive' episodes alone. For example, Malmberg, Järvenoja and Järvelä (2017) explored the sequential patterns of self-, co-, and socially-shared regulation of learning in the context of collaborative learning but focused solely on cognitive and metacognitive processes. While this body of research has progressed well, providing understanding, for example, of temporal manifestation and patterns of regulated learning in individual and group contexts (e.g., Molenaar \& Chiu, 2014; Sonnenberg \& Bannert, 2015; Zheng \& Yu, 2016), it still has often undermined the salience of motivational and affective processes and beliefs (Hadwin et al., 2017). Process-oriented methodology that is not limited only to observations, could offer possibilities for systematic analysis that integrates motivation and emotion regulation with the temporal analysis regulated learning more expansively.

Currently, we are progressing in our analysis of different motivational and emotional indicators that contribute to the process of regulated learning and provide evidence on how motivation and emotion regulation plays a role in group interaction during collaborative learning (Järvenoja et al., 2015; Malmberg et al., 2017; Malmberg, Järvelä, Holappa, Haataja, Siipo, \& Huang, 2018). At the moment, we are exploring how the research on motivation and emotion regulation in collaborative learning could benefit from implementation of physiological measures. Combining physiological measures with situated, process-oriented approaches is an uninvestigated area that has a potential to advance previous research regarding the influence of motivation and emotion regulation on learning and achievement. However, we argue that accurate inferences about motivation and emotion regulation require objective data to be carefully contextualised by subjective data about learners' intents and beliefs in the same relative moment. For example, Ahmed, van der Werf, and Minnaert (2010) combined multi-method qualitative methods and a physiological reactivity measure to investigate students' emotional experiences in the classroom and Henriques, Paiva, and Antunes (2013) measured electrodermal activity to access emotional patterns occurring in affective interactions. Physiological measures have also been used to complement video and log data to filter, organise and classify data into meaningful episodes according to the criteria derived from the theoretical justification and research focus (Appelhans \& Luecken, 2006; McRae et al. 2012). In relation to the regulation processes in collaborative learning, Haataja, Malmberg, and Järvelä (2018) studied physiological concordance (PC) of group members' electrodermal activity and observed regulation episodes, and found a weak positive connection between them. How to relate individual physiological reactions to the regulation of emotion or motivation during collaborative learning, however, is still to be explored. Therefore, we next present an example from our current, on-going study to explore the possibilities of implementing physiological data in recognising and tracing emotion and motivation regulation in the course of collaborative learning. In the following example, we are measuring collaborative group members' electrodermal activity from the skin to depict temporal variations in their physiological arousal (see 
also Ahonen, Cowley, Hellas, \& Puolamäki, 2018; Gillies et al., 2016). To contextualise the physiological data, we relate it with video data codings of valence in socio-emotional episodes (see example in Claim 2), which considered as potential indications of situations in which group members' joint co- and socially-shared emotion and motivation regulation can emerge. Ultimately, we aim for more systematic evidence of how motivation and emotion regulation is affecting the temporal progress of collaborative learning.

The example derives from the same data set presented under Claim 2 (Kurki, et al., 2018). To reveal the complexity of motivation and emotion regulation in collaborative learning, we collected two types of process data, $360^{\circ}$ video data and electrodermal activity (EDA) gathered with Empatica E4 wristbands (Garbarino, Lai, Bender, Picard, \& Tognetti, 2015). The analysis started by processing the data from two different channels separately. The video data processing was founded on the data coding presented in the Claim 2. The initial coding included indications of different learning phases (brainstorming, planning and building), locating socio-emotional interaction episodes (Järvenoja et al., 2017; Linnenbrink-Garcia, Rogat, \& Koskey, 2011), defining the groups' emotional valence during the socio-emotional interaction episodes, and, finally, searching for regulation of motivation and emotion in relation to these episodes (Järvelä, et al., 2016). With EDA data, we focused on the phasic skin conductance response (SCR) peaks as the former research had indicated that SCR peaks are strongly associated with emotional responses that are related to significant external stimulus. Hence, SCR peaks are considered more reactive to variations in experimental conditions than tonic skin conductance level (SCL) (Christopoulos, Uy, \& Yap, 2016; Dawson, Schell, \& Filion, 2007). After collecting the physiological data, it was first imported to Empatica E4 Connect software. The physiological EDA data was then processed using Python software and Microsoft Excel. Three groups had to be left out of the analysis in this initial data processing phase due to poor quality data of some of the group members. The baseline was computed using a third-order low-pass filter and SCR peaks were detected using the minimum value of $0.05 \mu \mathrm{S}$ between the baseline and peak (Boucsein, 2012; Dawson, Schell, \& Filion, 2007). Figure 1 shows an example of one group member's raw EDA data visualized in Empatica E4 Connect software (A) and processed EDA data with detected SCR peaks (B) which was used later in the analysis.
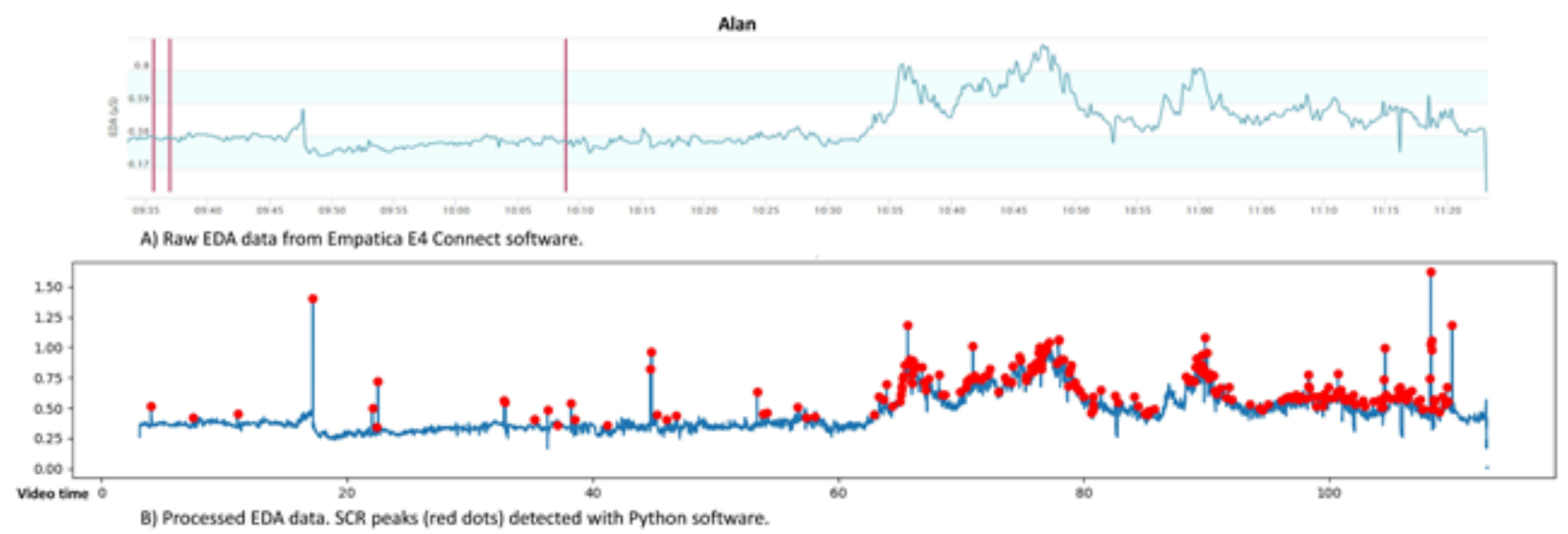

Figure 1. An example of the visualisation of one group member's raw EDA data extracted from Empatica E4 Connect software (A) and how the raw data was processed on the individual level to track SCR peaks (B).

After processing both video data and EDA data independently, the analysis proceeded to group-level analysis, which combined coded video data and physiological data. Already in the data collection phase, the video cameras and Empatica wristbands were synchronized, which enabled us to find timely commensurable indicators of the groups' emotional state from two different data channels. In this phase of the analysis, both video and EDA data were segmented in 30-second segments to make the data commensurable for further analysis. The 30-second time frame was chosen based on the preliminary socio-emotional episode coding of three videos, which defined the mean duration of coded episodes to 24.6 seconds. The segmentation proceeded by re-coding the whole video data corpus in terms of group members' socio-emotional interaction into the 30second segments. This coding was a dichotomous yes/no coding based on group members' visible emotional expressions (Table 1). The segments that included no emotional expressions or expressions only from one group member were considered as neutral in terms of the groups' emotional state and were not analysed further. 
The segments including socio-emotional expressions were categorised according the valence of groups' emotional state (positive, negative, mixed, unclear) and group-level emotion regulation, namely co- and socially-shared regulation and was performed for $40 \%$ of the coded videos using Cohen's kappa statistics. Substantial agreement was reached for both socio-emotional segment $(\kappa=0.693)$ and valence $(\kappa=0.723)$ coding.

EDA data was further processed by determining the frequency of each group members' SCR peaks in each 30-second segment. When both data sets were processed independently, they were synchronised based on the timestamps. To explore the possible association between the two sets of data as a whole, the relation between EDA segments and video observation segments was explored with chi-square statistics. For this purpose, the data on SCR peaks was reorganised into group level by categorizing each segment based on how many group members $(0,1,2,3)$ were having SCR peaks in the segment. Significant associations between observed segments and EDA segments were further explored with significant $z$ scores from adjusted residuals with alpha levels $0.05(z<1.96)$ and $0.001(z<2.58)$. As the chi-square test showed a significant relation between socio-emotional expressions observed and number of group inter-rater reliability analysis members with SCR peaks in the segment $\left(\chi^{2}(3)=27.106, p<0.000\right)$, the analysis was continued by exploring this relationship in more detail within groups. Altogether, 95 segments in which all group members are having SCR peaks and group-level valence were found. Figure 2 presents a three-member case group example of how the video data codings and EDA data were combined (Törmänen, Järvenoja, Kurki, Devai, \& Järvelä, 2018). In Figure 2, the frequency of each group member's (Jenny, Alan and Miia) individual SCR peaks in the situation is compared with the group-level valence coding to illustrate the associations between the observed emotional reactions and physiological reactions. The segments in which all three group members had SCR peaks as well as emotional expressions in the video are highlighted with vertical, coloured bars. As can be seen from the Figure 2, most of these situations occur at the end of the task, indicating that most of the emotionally activating sequences in this case group were located to the end of the collaborative learning activity.

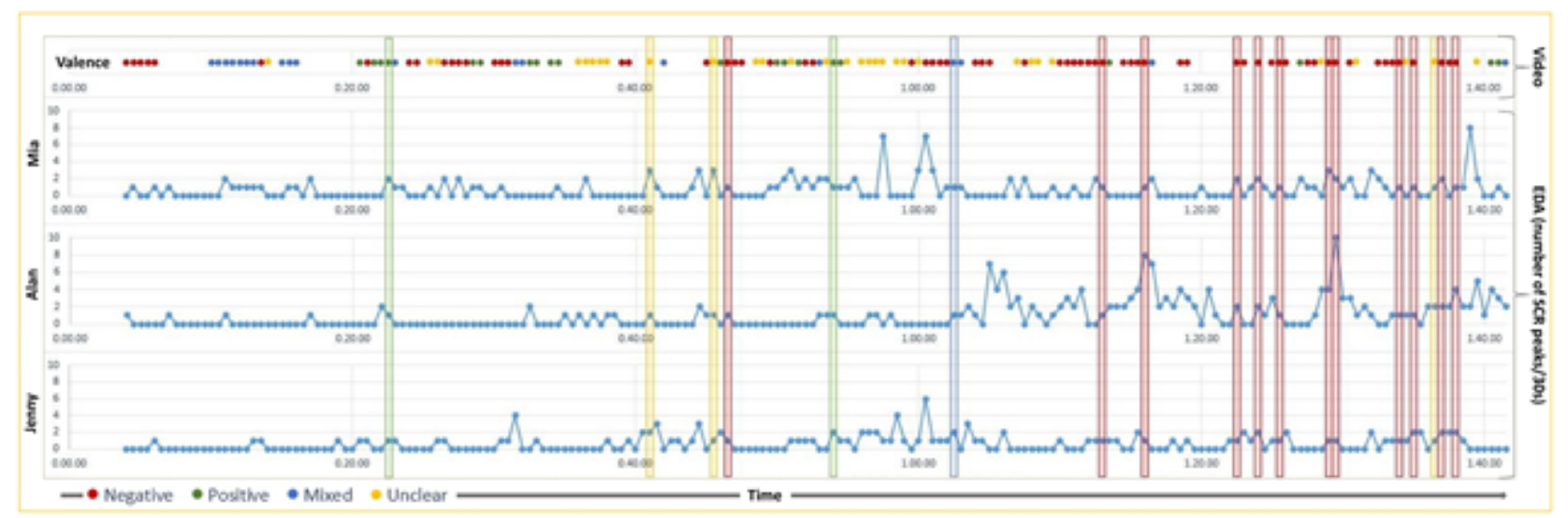

Figure 2. Example of the analysis that combines data from two data channels, namely (1) valence (red, green, yellow, and blue dots) detected from the video data and (2) the number of skin conductance response (SCR) peaks (blue line) from the EDA data. To detect emotionally activating situations on a group level, segments in which all group members are having SCR peaks and also expressing emotions in the video are located from the learning session (coloured segments) (Törmänen et al., 2018).

Next, we progressed into combining the motivation and emotion regulation coding into the analysis. Our assumption was that activating motivation and emotion regulation at the group level requires a trigger, for example a socio-emotionally challenging situation that invites the group members to regulate emotions and maintain motivation (Hadwin et al., 2017). That is why we will explore how the sequences that were located by combining SCR peaks with group level valence in the previous analysis phase are related with the co- and socially-shared regulation episodes coded from the video data. From 95 emotionally activating segments, $28 \%$ included either co- or socially-shared regulation. This is significantly more than the occurrence of co- and 
socially shared motivation and emotion regulation in the whole data set. These preliminary results indicate that when physiological reactions, namely peaks in SCR and observable emotional reactions in a group occur at the same time, they together may indicate a presence of a situational trigger that invites the group members to activate motivation and emotion regulation. However, further in-depth exploration needs to be conducted for the located segments to find the common situational characteristics, regardless whether they are cognitive, motivational or emotional, that determine the trigger features of these situations and consequently relate them with the coded motivation and emotion regulation. It should be noticed as well that a significant amount of motivation and emotion regulation was not located with this analytical approach. In the future, we need to explore whether some of these episodes would be better tracked by using some other features of motivation, emotions or physiological data. From the EDA data, moments of physiological concordance (PC), for example, could be explored in relation to the video coding (see e.g., Haataja, et al., 2018).

The type of analysis presented above has a clear advantage in that it combines data sources that derive from the same situation and target the same process. However, when with EDA data analysis, the interpretation is not as straightforward as with video data. In addition, the challenge in adding the physiological data is that it adds a new data channel and consequently new layer of analysis to an already complex combination of data sources and analysis dimensions. Therefore, careful consideration is needed when combining data with different foci (i.e., individual- or group-level data) and granularities (i.e., millisecond versus minutes of episodes as a unit of analysis) in a theoretically meaningful and empirically valid analysis. These analyses also face challenges with the granularity of the basic unit of the analysis. For example, the sampling rate of the Empatica E4 wristband is $4 \mathrm{~Hz}$ (that is, four times per second) (Garbarino et al., 2015), whereas a meaningful time span for video data coding covers sequences that span from a few seconds to episodes lasting several minutes. In the example above, we presented how we managed to match the two originally very different time scales together in a timely manner. We are still struggling, however, with how to match motivation and emotion regulation with this analysis. The main challenge seems to lie in the fact that within the group, the emotion and motivation regulation is not activated every time the valence coding and SCR peaks indicate potential for it. In addition, regulation does not fall in the same time sequence frequency with the two other dimensions; the SCR peaks and valence are more instant reactions while regulation requires awareness that is created through (metacognitive) monitoring, which is not instant. Accordingly, our data seems to indicate that there can be a lag between the emotional reactions and activated regulation. In addition, the temporal dependence of the time series data and physical movement, should be taken into consideration.

Finally, it is possible we have not yet found the right indicators of the triggers that activate regulation and which act as mediators between physiological reactions and the actualised regulation. The physiological data in general, and electrodermal activity particularly, challenge us to consider what the meaningful physiological indicators regarding groups' emotional experiences, learning and interaction are in the first place. That is, physiological reactions are just reactions and are meaningless for possible regulation without individual motivational and emotional interpretations of the situation. EDA, for example, is a signal related to the intensity of arousal, meaning that it does not provide information on the quality of the valence of students' emotional states, not to mention regulation (Eiser, 1986). Therefore, EDA is a measure that provides quantitative properties, while the determination of qualitative properties requires measures of subjective interpretations and measures that provide a meaningful context to explain the reactions captured with the physiological measures (Boucsein, 2012; Immordino-Yang, Christodoulou, Pekrun, \& Linnenbrink-Garcia, 2014). Thus, we still need to explore in more detail the theoretically meaningful associations between different layers of the multiple data before this analysis can truly add to our understanding of the role of motivation and emotion regulation in learning. When this is accomplished, this type of methodological design will enable extension to open in real life learning settings.

\section{Conclusion}

Through the three claims and related examples presented in this paper, we described our research approach, which emphasises the role of motivation and emotion regulation in the regulated learning process (Ben-Eliyahu \& Linnenbrink-Garcia, 2013; Duffy et al., 2015; Järvelä et al., 2016; Kwon, Liu, \& Johnson, 2014; Rogat \& Adams-Wiggins, 2015). The three claims highlighted a particular viewpoint to the approach: a requisite to study motivation and emotion regulation as situated in the learning context, a need to acknowledge 
both the process in which regulation is actualised as well as individuals' subjective beliefs and appraisals of these processes, and finally, a possibility to understand and capture motivation and emotion regulation by tracking related indicators from learning process. In relation to each claim, we discussed the advantages and challenges we have faced regarding to that claim.

Most of the advantages and the challenges we have faced are not related only to one of the claims. Instead, when putting the research in action, the different claims become intertwined and the pros and cons of our approach derive from this entity. This was realized in the empirical data examples presented in relation to Claims 2 and 3. The examples derived from a single data collection, and together they showcased our endeavour to capture motivation and emotion regulation by implementing multiple and complementary methods. Together, the examples illustrated particularly, how we have utilized the concept of valence as a theoretical construct to indicate potential for motivation and emotion regulation to emerge. Valence proved to be useful as it was possible to measure or locate it from data deriving from different sources. Hence, valence mediated the combination of different data channels of subjective interpretations, observable (inter)actions and physiological reactions. It was also theoretically connectable with motivation and emotion regulation depicted from video as well as with physiological arousal collected with the Empatica wristbands. The example in relation to Claim 3 showed that by combining valence and arousal levels within a group, we were able to increase the probability of finding episodes of motivation and emotion regulation to some extent. To conclude, by adding to our analysis of motivation and emotion regulation a well-defined construct that better determined the nature of socio-emotional interaction, we were also better able to utilize the different data channels in the comprehensive analysis. While the process is still on-going, focusing on constructs, which can be clearly operationalised, appears promising to find the systematic way to locate and trace motivation and emotion regulation in action.

However, we are still facing significant challenges with the large and complex data sets that are context specific (Azevedo, 2015; Bannert, Reimann, \& Sonnenberg, 2014; Gašević, Dawson, \& Siemens, 2015). It is evident that a single operationalised indicator, in our case valence, is not solely enough to indicate the triggers that activate groups' shared motivation and emotion regulation. It is presumably that we need more than one indicator - a set of operationalised indicators - to be able to efficiently employ the potential of physiological reactions in tracing more comprehensively the situations where motivation and emotion regulation emerges. The complex designs produce a significant amount of multiple data, but 'more data' does not inevitably lead to 'deeper data' with meaningful results (Reimann, Markauskaite, \& Bannert, 2014). Although the data is rich and allows opportunities to reach motivation and emotion regulation in parallel with, for example, the analysis of other regulatory processes, these operationalised indicators are essential to manage with the complexity and richness of the multiple data channels each producing raw data from different processes and levels.

In addition, the examples presented here still concern a relatively small data set in which the learning process is shaped by the complexities of different contextual and situational aspects encountered in real-life learning situations. Therefore, it suffers from the inability to differentiate between the more and less meaningful indicators in tracing motivation and emotion regulation. Baker, Hershkovitz, Rossi, Goldstein, and Gowda (2013) pointed out that a major limitation of multi-layered data analysis, including video observations, has difficulty in scaling large amounts of data or large numbers of students. Tracing different motivational and emotional variables 'moment to moment' has the potential to reveal the antecedent and consequences of motivation and emotion regulation. This is needed to explain (successful) emotion and motivation regulation, but the current limitation is that with the amount of data we are able to process at the moment, it is difficult to interpret the relations and meaningfulness of these moment-to-moment indicators for regulation and further, to groups' learning. New analysis methods, such as educational data mining or timeseries methods could be useful in the future to be able to search for dependencies between triggers and occurrence of motivation or emotions within the group also from larger sets of data.

We conclude that capturing motivation and emotion regulation means knowing something about learners' internal perceptions and intent and relating that with the (inter)actions in the current situation (Wise $\&$ Schwartz, 2017). Social interactions, sequences and patterns need to be further contextualised in larger episodes of activity with attention to individual and collective goals, plans and reflection to delineate metacognitively-driven regulatory processes versus extemporaneous patterns of interaction (Järvelä et al., 2017). We argue that even with the cost of future errors and mistakes, this endeavour of unlocking the regulated learning process through the analysis of data gained from multiple data channels has the potential to produce 
knowledge regarding groups' motivated learning and regulation. We further argue for the importance of drawing upon multiple analytical methods and invite scholars to multidisciplinary collaboration (e.g., data scientists) to examine the data and multiple modes of motivation and emotion regulation as they operate and support (or hinder) learning and collaboration. These studies can take important steps towards overcoming the dichotomy between modes of regulation, such as cognition, metacognition, motivation and emotion and instead examine the interplay between them.

\section{Keypoints}

- Research approach to study motivation and emotion regulation in learning process is introduced.

- Motivation and emotion regulation is situation and context specific.

- Motivation and emotion regulation is influenced by multi-layered nature of motivation.

- Motivation and emotion regulation is intertwined with other processes of learning and can be captured from their temporal manifestation.

- Multiple data channels can help to capture the motivation and emotion regulation from the process data

\section{Acknowledgments}

This work was supported by the Finnish Academy [grant number 297686; 24302574; 316129].

\section{References}

Ahmed, W., van der Werf, G., \& Minnaert, A. (2010). Emotional experiences of students in the classroom: A multimethod qualitative study. European Psychologist, 15(2), 142-151. http://dx.doi.org/10.1027/1016$\underline{9040 / \mathrm{a} 000014}$

Ahonen, L., Cowley, B. U., Hellas, A., \& Puolamäki, K. (2018). Biosignals reflect pair-dynamics in collaborative work: EDA and ECG study of pair-programming in a classroom environment. Scientific Reports, 8(1), 1-16. https://doi.org/10.1038/s41598-018-21518-3

Appelhans, B. M., \& Luecken, L. J. (2006). Heart rate variability as an index of regulated emotional responding. Review of General Psychology, 10(3), 229-240. http://dx.doi.org/10.1037/10892680.10.3.229

Azevedo, R., Moos, D. C., Johnson, A.M., \& Chauncey, A. D. (2010). Measuring cognitive and metacognitive regulatory processes during hypermedia learning: Issues and challenges. Educational psychologist 45(4), 210-223. https://doi.org/10.1080/00461520.2010.515934

Azevedo, R. (2015). Defining and Measuring Engagement and Learning in Science: Conceptual, Theoretical, Methodological, and Analytical Issues. Educational Psychologist, 50(1), 84-94. https://doi.org/10.1080/00461520.2015.1004069

Baker, M. J. (2015). Collaboration in collaborative learning. Interaction Studies, 16, 451-473. https://doi.org/10.1075/is.16.3.05bak 
Baker, R. S., Hershkovitz, A., Rossi, L. M., Goldstein, A. B., \& Gowda, S. M. (2013). Predicting Robust Learning With the Visual Form of the Moment-by-Moment Learning Curve. Journal of the Learning Sciences, 22(4), 639-666. https://doi.org/10.1080/10508406.2013.836653

Bakhtiar, A., Webster, E. A., \& Hadwin, A. F. (2018). Regulation and socio-emotional interactions in a positive and a negative group climate. Metacognition and Learning, 13(1), 57-90.

https://doi.org/10.1007/s11409-017-9178-x

Bandura, A. (2011). On the Functional Properties of Perceived Self-Efficacy Revisited. Journal of Management, 38(1), 9-44. https://doi.org/10.1177/0149206311410606

Bannert, M., Reimann, P., \& Sonnenberg, C. (2014). Process mining techniques for analysing patterns and strategies in students' self-regulated learning. Metacognition and Learning, 9(2), 161-185. https://doi.org/10.1007/s11409-013-9107-6

Basil-Shachar, J., Hod, Y., \& Ben-Zvi, D. (2015). The emergence of norms in a technology-enhanced learning community. In O. Lindwall, P. Koschman, T. Tchounikine, \& S. Ludvigsen (Eds.), Exploring the Material Conditions of Learning: The Computer Supported Collaborative Learning Conference (CSCL), Volume II (pp. 807-808). Gothenburg, Sweden: The International Society of the Learning Sciences.

Ben-Eliyahu, A., \& Linnenbrink-Garcia, L. (2013). Extending self-regulated learning to include self-regulated emotion strategies. Motivation and Emotion, 37(3), 558-573. https://doi.org/10.1007/s11031-012-9332$\underline{3}$

Berger, J. L., \& Karabenick, S. A. (2011). Motivation and students' use of learning strategies: Evidence of unidirectional effects in mathematics classrooms. Learning and instruction, 21 (3), 416-428.Boekaerts, M., \& Corno, L. (2005). Self regulation in the classroom: A perspective on assessment and intervention. Applied Psychology, 54(2), 199-231. https://doi.org/10.1111/j.1464-0597.2005.00205.x

Boekaerts, M., \& Pekrun, R. (2015). Emotions and emotion regulation in academic settings. In L. Corno \& E. M. Anderman (Eds). Handbook of educational psychology ( $3^{\text {rd }}$ ed.) (pp. 76-90). Routledge

Boucsein, W. (2012). Electrodermal activity. Springer Science \& Business Media., 1-8. https://doi.org/10.1007/978-1-4614-1126-0

Christopoulos, G. I., Uy, M. A., \& Yap, W. J. (2016). The Body and the Brain: Measuring Skin Conductance Responses to Understand the Emotional Experience. Organizational Research Methods, 1-27. https://doi.org/10.1177/1094428116681073

Cleary, T. J. (2006). The development and validation of the Self-Regulation Strategy Inventory-Self-Report. Journal of School Psychology, 44(4), 307-322. https://doi.org/https://doi.org/10.1016/j.jsp.2006.05.002

Dawson, M. E., Schell, A. M., \& Filion, D. M. (2007). The Electrodermal System. In J. Cacioppo, L. G. Tassinary, \& G. G. Berntson (Eds.), Handbook of Psychophysiology (3rd ed., pp. 159-181). Cambridge: Cambridge University Press.

Dignath, C., Buettner, G., Langfeldt, H.-P., \& Goethe, J. W. (2008). How can primary school students learn self-regulated learning strategies most effectively? Educational Research Review, 3(2), 101-129. https://doi.org/10.1016/j.edurev.2008.02.003

Dowson, M., \& McInerney, D. M. (2003). What do students say about their motivational goals? Towards a more complex and dynamic perspective on student motivation. Contemporary Educational Psychology, 28(1), 91-113. https://doi.org/10.1016/S0361-476X(02)00010-3

Duffy, M. C., Azevedo, R., Sun, N. Z., Griscom, S. E., Stead, V., Crelinsten, L., ... Lachapelle, K. (2015). Team regulation in a simulated medical emergency: An in-depth analysis of cognitive, metacognitive, and affective processes. Instructional Science, 43(3), 401-426. https://doi.org/10.1007/s11251-0149333-6

Eiser, J. R. (1986). Social psychology: Attitudes, cognition and social behaviour. Cambridge University Press. 
Elliot, A. J., Aldhobaiban, N., Kobeisy, A., Murayama, K., Gocłowska, M. A., Lichtenfeld, S., \& Khayat, A. (2016). Linking social interdependence preferences to achievement goal adoption. Learning and Individual Differences, 50, 291-295.

Fincham, O. E., Gasevic, D. V., Jovanovic, J. M., \& Pardo, A. (2018). From Study Tactics to Learning Strategies: An Analytical Method for Extracting Interpretable Representations. IEEE Transactions on Learning Technologies.

Garbarino, M., Lai, M., Bender, D., Picard, R. W., \& Tognetti, S. (2015). Empatica E3 - A wearable wireless multi-sensor device for real-time computerized biofeedback and data acquisition. Proceedings of the 2014 4th International Conference on Wireless Mobile Communication and Healthcare - "Transforming Healthcare Through Innovations in Mobile and Wireless Technologies”, MOBIHEALTH 2014, 39-42. https://doi.org/10.1109/MOBIHEALTH.2014.7015904

Gašević, D., Dawson, S., \& Siemens, G. (2015). Let's not forget: Learning analytics are about learning. TechTrends, 59(1), 64-71.

Gillies, R. M., Carroll, A., Cunnington, R., Rafter, M., Palghat, K., Bednark, J., \& Bourgeois, A. (2016). Multimodal representations during an inquiry problem solving activity in a Year 6 science class: A case study investigating cooperation, physiological arousal and belief states. Australian Journal of Education, $O(0), 117$. https://doi.org/10.1177/0004944116650701

Greeno, G. J. (2005). Learning in Activity. In R. K. Sawyer (Ed.), The Cambridge Handbook of the Learning Sciences (pp. 79-96). Cambridge: Cambridge University Press. https://doi.org/DOI: 10.1017/CBO9780511816833.007

Griffin, P., McGaw, B., \& Care, E. (2012). The Changing Role of Education and Schools. In P. Griffin, B. McGaw, \& E. Care (Eds.), Assessment and Teaching of 21st Century Skills (pp. 1-16). Dordrecht, Germany: Springer Science+Business Media B.V. http://dx.doi.org/10.1007/978-94-007-2324-5_2

Haataja, E., Malmberg, J., \& Järvelä, S. (2018). Monitoring in collaborative learning: Co-occurrence of observed behavior and physiological synchrony explored. Computers in Human Behavior, 87(June), 337347. https://doi.org/10.1016/j.chb.2018.06.007

Hadwin, A. F., Järvelä, S., \& Miller, M. (2017). Self-regulation, co-regulation and shared regulation in collaborative learning environments. In D. Schunk \& J. Greene (Eds.), Handbook of Self-Regulation of Learning and Performance (2nd ed.). New York, NY: Routledge.

Henriques R., Paiva A., \& Antunes C. (2013) On the Need of New Methods to Mine Electrodermal Activity in Emotion-Centered Studies. In: Cao L., Zeng Y., Symeonidis A.L., Gorodetsky V.I., Yu P.S., Singh M.P. (eds) Agents and Data Mining Interaction. ADMI 2012. Lecture Notes in Computer Science, vol 7607. Springer, Berlin, Heidelberg

Hickey, D. T., \& McCaslin, M. (2001). A comparative, sociocultural analysis of context and motivation. In S. Volet \& S. Järvelä (Eds.), Advances in learning and instruction series. Motivation in learning contexts: Theoretical advances and methodological implications (pp. 33-55). Elmsford, NY: Pergamon Press.

Immordino-Yang, M. H., Christodoulou, J. A., Pekrun, R., \& Linnenbrink-Garcia, L. (2014). Neuroscientific contributions to emotion measurement in educational contexts. In Handbook of Emotions in Education (pp. 607-624). New York: Routledge.

Isohätälä, J., Järvenoja, H., \& Järvelä, S. (2017). Socially shared regulation of learning and participation in social interaction in collaborative learning. International Journal of Educational Research, 81, 11-24. https://doi.org/10.1016/j.ijer.2016.10.006

Järvelä, S., \& Hadwin, A. F. (2013). New Frontiers: Regulating Learning in CSCL. Educational Psychologist, 48(1), 25-39. https://doi.org/10.1080/00461520.2012.748006

Järvelä, S., Järvenoja, H., \& Veermans, M. (2008). Understanding the dynamics of motivation in socially shared learning. International Journal of Educational Research, 47, 122-135. 
Järvelä, S., Järvenoja, H., Malmberg, J., Isohätälä, J., \& Sobocinski, M. (2016). How do types of interaction and phases of self-regulated learning set a stage for collaborative engagement? Learning and Instruction, 43, 39-51. https://doi.org/10.1016/j.learninstruc.2016.01.005

Järvelä, S., Malmberg, J., Sobocinski, M., Haataja, E., \& Kirschner, P. (2018). What multimodal data tell about self regulated learning process? Submitted.

Järvelä, S., Salonen, P., \& Lepola, J. (2001). Dynamic assessment as a key to understanding student motivation in a classroom context. In Pintrich, P., \& Maehr, M. (Eds.), Advances in motivation and achievement (pp.207-240). Amsterdam: JAI Press.

Järvenoja, H., \& Järvelä, S. (2009). Emotion control in collaborative learning situations - Do students regulate emotions evoked from social challenges? British Journal of Educational Psychology, 79, 463-481. doi:10.1348/000709909X402811

Järvenoja, H., Järvelä, S., \& Malmberg, J. (2015). Understanding Regulated Learning in Situative and $\begin{array}{llll}\text { Contextual Frameworks. } & \text { Educational }\end{array}$ https://doi.org/10.1080/00461520.2015.1075400

Järvenoja, H., Järvelä, S., \& Malmberg, J. (2017). Supporting groups' emotion and motivation regulation during collaborative learning. Learning and Instruction, (November), 0-1. https://doi.org/10.1016/j.learninstruc.2017.11.004

Järvenoja, H., Näykki, P., Törmänen, T. \& Järvelä, S. (2018). Emotional regulation in collaborative learning: When do higher education students activate group level regulation in the face of challenges? Submitted.

Järvenoja, H., Volet, S., \& Järvelä, S. (2013). Regulation of emotions in socially challenging learning situations: an instrument to measure the adaptive and social nature of the regulation process. Educational Psychology, 33, 31-58. https://doi.org/10.1080/01443410.2012.742334

Kirschner, F., Paas, F., \& Kirschner, P. A. (2011). Task Complexity and Collaborative Learning Efficiency: The Collective Working-Memory Effect. Applied Cognitive Psychology, 25, 615-624.

Koskey, K. L. K., Karabenick, S. A., Woolley, M. E., Bonney, C. R., \& Dever, B. V. (2010). Cognitive validity of students' self-reports of classroom mastery goal structure: What students are thinking and why it matters. Contemporary Educational Psychology, 35(4), 254-263. http://dx.doi.org/10.1016/j.cedpsych.2010.05.004

Kreibig, S. D. (2010). Autonomic nervous system activity in emotion: A review. Biological Psychology, 84(3), 394-421. https://doi.org/10.1016/j.biopsycho.2010.03.010

Kurki, K., Järvenoja, H., Järvelä, S., \& Mykkänen, A. (2017). Young children's use of emotion and behaviour regulation strategies in socio-emotionally challenging day-care situations. Early Childhood Research Quarterly, 41(June 2016), 50-62.https://doi.org/10.1016/j.ecresq.2017.06.002

Kurki, K., Järvenoja, H., Törmänen, T. \& Bakhtiar, A. (2018). Socio-emotional interaction in collaborative learning: Combining individual emotional experiences and group level regulation. Paper presented at International Conference on Motivation, Aarhus.

Kwon, K., Liu, Y. H., \& Johnson, L. P. (2014). Group regulation and social-emotional interactions observed in computer supported collaborative learning: Comparison between good vs poor collaborators. Computers and Education, 78, 185-200. https://doi.org/10.1016/j.compedu.2014.06.004

Levy, I., Kaplan, A., \& Patrick, H. (2004). Early adolescents' achievement goals, social status, and attitudes towards cooperation with peers. Social Psychology of Education, 7(2), 127-159.

Linnenbrink-Garcia, L., \& Pekrun, R. (2011). Students' emotions and academic engagement: Introduction to the special issue. Contemporary Educational Psychology, 36(1), 1-3. https://doi.org/10.1016/j.cedpsych.2010.11.004 
Linnenbrink-Garcia, L., Rogat, T. K., \& Koskey, K. L. K. (2011). Affect and engagement during small group instruction. Contemporary Educational Psychology, 36(1), 13-24. https://doi.org/10.1016/j.cedpsych.2010.09.001

Malmberg, J., Järvelä, S., Holappa, J., Haataja, E., \& Siipo, A, Huang, X. (2018).Going beyond what is visible -What physiological measures can reveal about regulated learning in the context of collaborative learning? Computers and Human Behavior.

Malmberg, J., Järvelä, S., \& Järvenoja, H. (2017). Capturing temporal and sequential patterns of self-, co-, and socially shared regulation in the context of collaborative learning. Contemporary Educational Psychology, 49, 160-174. https://doi.org/10.1016/j.cedpsych.2017.01.009

Malmberg, J., Järvenoja, H., \& Järvelä, S (2013). Patterns in elementary school students' strategic actions in varying learning situations. Instructional Science. DOI 10.1007/s11251-012-9262-1

Mccardle, L., \& Hadwin, A. (2015). Using multiple, contextualized data sources to measure learners' perceptions of their self-regulated learning. Metacognition and Learning (Vol. 10). https://doi.org/10.1007/s11409-014-9132-0

McRae, K., Gross, J. J., Weber, J., Robertson, E. R., Sokol-Hessner, P., Ray, R. D., ... Ochsner, K. N. (2012). The development of emotion regulation: an fMRI study of cognitive reappraisal in children, adolescents and young adults. Social Cognitive and Affective Neuroscience, 7(1), 11-22. http://doi.org/10.1093/scan/nsr093

Miyake, N. (1986). Constructive interaction and the iterative process of understanding. Cognitive Science, 10, 151-177. doi: 10.1207/s15516709cog1002_2

Molenaar, I., Chiu, M. M. (2014). Dissecting sequences of regulation and cognition: Statistical discourse analysis of primary school children's collaborative learning. Metacognition and Learning, 9, 137-160. doi:10.1007/s11409-013-9105-8

Mykkänen, A., Perry, N., \& Järvelä, S. (2017). Finnish students' reasons for their achievement in classroom activities: focus on features that support self-regulated learning. Education 3-13, 45(1), 1-16. https://doi.org/10.1080/03004279.2015.1025802

Näykki, P., Isohätälä, J., Järvelä, S., Pöysä-Tarhonen, J., \& Häkkinen, P. (2017). Facilitating socio-cognitive and socio-emotional monitoring in collaborative learning with a regulation macro script - an exploratory study. International Journal of Computer-Supported Collaborative Learning, 12(3), 251-279. https://doi.org/10.1007/s11412-017-9259-5

Näykki, P., Järvelä, S., Kirschner, P. A., \& Järvenoja, H. (2014). Socio-emotional conflict in collaborative learning-A process-oriented case study in a higher education context. International Journal of Educational Research, 68, 1-14.https://doi.org/10.1016/j.ijer.2014.07.001

Nolen, S. B. (2006). Validity in assessing self-regulated learning: A comment on Perry \& Winne. Educational Psychology Review, 18(3), 229-232. https://doi.org/10.1007/s10648-006-9016-1

Nolen, S. B., Horn, I. S., \& Ward, C. J. (2015). Situating Motivation. Educational Psychologist, 50(3), 234247. https://doi.org/10.1080/00461520.2015.1075399

Ochoa, X. (2017). Multimodal Learning Analytics. In C. Lang, G. Siemens, A. Wise, \& D. Gasevic (Eds.), Handbook of Learning Analytics (pp. 129-141). SOLAR. Society for Learning Analytics Research.

Paris, S. G., \& Turner, J. C. (2012). Situated motivation. In Student motivation, cognition, and learning (pp. 229-254). Routledge.Pekrun, R. (2016). Academic emotions. In K. R, Wentzel, D. B. Miele (Eds.), Handbook of motivation at school (pp.120-146). New York, NY: Routledge.

Pekrun, R., Goetz, T., Titz, W., \& Perry, R. P. (2002). Academic Emotions in Students' Self-Regulated Learning and Achievement: A Program of Qualitative and Quantitative Research. Educational Psychologist, 37(2), 91-106. https://doi.org/10.1207/S15326985EP3702 
Pintrich, P. R. (2000). The role of goal orientation in self-regulated learning. In M. Boekaerts. P.R. Pintrich \& M. Zeidner (Eds.), Handbook of Self-Regulation, (pp. 451-502) San Diego, CA: Academic Press.

Pintrich, P. R. (2003). Multiple goals and multiple pathways in the development of motivation and selfregulated learning. In L. Smith, C. Rogers, \& P. Tomlinson (Eds.), Development and motivation: Joint perspectives (pp. 137-155). Leicester: British Psychological Society.

Reimann, P., Markauskaite, L. and Bannert, M. (2014), e-Research and learning theory. British Journal of Educational Technology, 45(3), 528-540. https://doi.org/10.1111/bjet.12146

Roschelle, J., \& Teasley, S. (1995). The construction of shared knowledge in collaborative problem solving. In C. E. O'Malley (Ed.), Computer-supported collaborative learning (pp. 69-97). Heidelberg: SpringerVerlag.

Rogat, T. K., \& Adams-Wiggins, K. R. (2015). Interrelation between regulatory and socioemotional processes within collaborative groups characterized by facilitative and directive other-regulation. Computers in Human Behavior, 52, 589-600. https://doi.org/10.1016/j.chb.2015.01.026

Russell, J. A., \& Barrett, L. F. (1999). Core affect, prototypical emotional episodes, and other things called emotion: Dissecting the elephant. Journal of Personality and Social Psychology, 76(5), 805-819. https://doi.org/10.1037/0022-3514.76.5.805

Sawyer, K. (2014). Introduction: The new science of learning. In R. K. Sawyer, (Ed.), The Cambridge handbook of the learning sciences (2nd ed., pp. 1-18). New York, NY: Cambridge University Press.

Schutz, P. A., \& Pekrun, R. (2007). Introduction to Emotion in Education. In P. A. Schutz \& R. Pekrun (Eds.), Emotion in Education (pp. 3-10). Burlington: Elsevier Inc.

Sobocinski, M., Malmberg, J., \& Järvelä, S. (2017). Exploring temporal sequences of regulatory phases and associated interactions in low- and high-challenge collaborative learning sessions. Metacognition and Learning (Vol. 12). https://doi.org/10.1007/s11409-016-9167-5

Sonnenberg, C., \& Bannert, M. (2015). Discovering the effects of metacognitive prompts on the sequential structure of SRL-process using process mining techniques. Journal of Learning Analytics, 2 (1), 72-100.

Törmänen, T., Järvenoja, H., Kurki, K., Devai, R., \& Järvelä, S. (2018, August). Students' emotional valence and physiological arousal during collaborative learning - A case study. Poster presented at $16^{\text {th }}$ International Conference on Motivation 2018, Aarhus, Denmark.

Usher, E. L., \& Pajares, F. (2008). Sources of Self-Efficacy in School: Critical Review of the Literature and Future Directions. Review of Educational Research, 78(4), 751-796. https://doi.org/10.3102/0034654308321456

Volet, S., \& Järvelä, S. (Eds.). (2001). Advances in learning and instruction series. Motivation in learning contexts: Theoretical advances and methodological implications. Elmsford, NY: Pergamon Press.

Volet, S., \& Vauras, M. (2013). Interpersonal regulation of learning and motivation: Methodological advances. New York: Routledge.

Volet, S., Vauras, M., \& Salonen, P. (2009). Self-and social regulation in learning contexts: An integrative perspective. Educational psychologist, 44(4), 215-226.Webb, N. M., Troper, J. D., \& Fall, R. (1995). Constructive activity and learning in collaborative small groups. Journal of Educational Psychology, 87(3), 406-423. doi: 10.1037/0022-0663.87.3.406

Whitebread, D., Coltman, P., Pasternak, D. P., Sangster, C., Grau, V., Bingham, S., ... Demetriou, D. (2009). The development of two observational tools for assessing metacognition and self-regulated learning in young children. Metacognition and Learning, 4, 63-85. https://doi.org/10.1007/s11409-008-9033-1

Winne, P. H., \& Hadwin, A. F. (1998). Studying as Self-Regulated Learning. In D. J. Hacker, J. Dunlosky, \& A. Graesser (Eds.), Metacognition in educational theory and practice (pp. 277-304). Hillsdale, NJ. 
Winne, P.H., \& Jamieson-Noel, D.L. (2002). Exploring students' calibration of self- reports about study tactics and achievement. Contemporary Educational Psychology , 27 , 551-572.

Winne, P.H., \& Perry, N.E. (2000). Measuring self-regulated learning. In P. Pintrich, M. Boekaerts \& M. Zeidner (Eds.), Handbook of self-regulation (pp. 531-566). Orlando, FL: Academic Press.

Wise, A. F., \& Schwarz, B. B. (2017). Visions of CSCL: eight provocations for the future of the field. International Journal of Computer-Supported Collaborative Learning, 12(4), 423-467.

Wolters, C. A., \& Benzon, M. B. (2013). Assessing and predicting college students' use of strategies for the self-regulation of motivation. The Journal of Experimental Education, 81(2), 199-221.Zheng, L., \& Yu, J. (2016). Exploring the behavioral patterns of co-regulation in mobile computer-supported collaborative learning. Smart Learning Environments, 3(1), 1-20.10.1186/s40561-016-0024-4

Zimmerman, B., \& Schunk, D. H. (Eds.). (2011). Handbook of self-regulation of learning and performance. New York, NY: Taylor \& Francis 